\title{
EL CUERPO JUVENIL SANO COMO SÍMBOLO POLÍTICO. LA NORMALIZACIÓN DE LOS CUERPOS A TRAVÉS DEL DISCURSO MÉDICO DEL FASCISMO
}

\author{
Marta Mauri Medrano \\ Universidad de Zaragoza, España \\ mmauri@unizar.es
}

\begin{abstract}
RESUMEN
Este articulo abordará, desde una perspectiva basada en la teoría foucaltiana de normalización corporal, el discurso médico pseucientífico que difundió el fascismo italiano, alemán y el franquismo en España con el objetivo de controlar a los jóvenes, normalizarlos según los cánones que marcaban las distintas organizaciones fascistas para conseguir una generación de muchachos sumisos, sanos, productivos y profundamente fascistas. Para el fascismo, el cuerpo pertenecía al Estado, a la Patria, con el objetivo de conseguir unos jóvenes fuertes y sanos que pudieran sostener sobre sus torsos el peso del Estado fascista y su expansión política futura. El cuerpo juvenil sano se convirtió en el símbolo político del fascismo.
\end{abstract}

Palabras clave: educación, fascismo, medicina.

\section{YOUTH AND HEALTHY BODY AS A POLITICAL SYMBOL. STANDARDIZATION OF MEDICAL CORPS THROUGH THE SPEECH OF FASCISM}

\begin{abstract}
This article will address, from a perspective based on Foucaultian theory of body standardization, who medical discourse that broad cast the Italian fascism, German and Franco in Spain with theaim of controlling the youth, normalize them. According to the canons that marked the different organizations fascists to get a generation of boys submissives, healthy, productive and deeply fascists. For Fascism, the body belonged to the state, with theaim of achieving a strong and healthy Young people who could hold their body son the weight of the fascist state and its political future expansion. The healthy and Young body became the political symbol of fascism.
\end{abstract}

Keywords: Education. Fascism. Health.

\section{O CORPO JUNEVIL SAUDÁVEL COMO SÍMBOLO POLÍTICO. A NORMALIZAÇÃO DOS CORPOS ATRAVÉS DO DISCURSO MÉDICO FASCISTA}

\section{RESUMO}

Este artigo abordará, por meio de de uma perspectiva baseada na teoria foucaultiana de normalização corporal, o discurso médico pseudocientífico que foi difundido pelo fascismo italiano, alemão e o franquismo espanhol, com o objetivo de controlar os jovens, normalizando-os segundo os cânones que marcavam as distintas organizações fascistas para conseguir uma geração de meninos submissos, saudáveis, produtivos e profundamente fascistas. Para o fascismo, o corpo pertencia ao Estado e à pátria, com o objetivo de conseguir jovens fortes e saudáveis que pudessem sustentar sobre seus torsos o peso do estado fascista e 
sua futura expansão política. O corpo juvenil saudável se tornou o símbolo político do fascismo.

Palavras-chave: Educação. Fascismo. Medicina.

\section{LE JEUNE CORPS SAIN COMME UN SYMBOLE POLITIQUE. ORGANISMES DE NORMALISATION À TRAVERS LE DISCOURS MÉDICAL DU FASCISME \\ RÉSUMÉ}

Cet article aborde, dans une perspective basée sur la théorie foucaldienne de la normalisation du corps, le discours médical pseudo-scientifique qui a diffusé le fascisme italien, allemand et le franquisme en Espagne, dans le but de contrôler les jeunes, les normaliser selon les canons qui ont marqué les différentes organisations fascistes pour obtenir une génération de garçons soumisses, sains, productifs et profondément fascistes. Pour le fascisme, le corps appartenait à l'État, à la Patrie, dans le but de obtenir des jeunes fortes et en bonne santé poursupporter le poids de l'Etat fasciste et son expansion politique a future. Le corps juvénile sain est devenu le symbole politique du fascisme.

Mots-clés: Education. Fascisme. Médecine.

\section{INTRODUCCIÓN}

El dominio del cuerpo se ha manifestado en el control de la movilidad, de la manera de vestir, del peinado e, incluso, de la mirada de todos aquellos que - como los escolares y los soldados - han sido internados históricamente en diversas instituciones. Así se explica la continuidad de los ejercicios gimnásticos que, durante décadas, uniformizaron el discurso corporal desde la escuela hasta el cuartel: los cuerpos también se han supeditado a los engranajes institucionales. El cuerpo se ha adaptado a los vaivenes de la Historia, a sus usos, costumbres, etc. Y se puede afirmar que el cuerpo es "el huésped silencioso de los signos de la cultura por lo que posee un alfabeto que es posible conocer y descodificar" (VILLANOU, 2001, p. 94).

Su constitución como temática se ha venido realizando en los últimos años - con avances significativos en la historiografía latinoamericana - y su construcción como materia de investigación parece ser una laberinto, debido a la multiplicidad de enfoques y perspectivas que pueden darse, dependiendo de las disciplinas y aún más dependiendo del uso de una fundamentación teórica en particular.

Según Foucault, el cuerpo fue construido y moldeado por el poder en las sociedades modernas, el cual es dividido en dos cuestiones separadas; por un lado la disciplina del cuerpo de los individuos - la anatomopolítica - y por otro el cuerpo de la población múltiple - la 
biopolítica. En palabras de Foucault, podemos apreciar que el micropoder opera en los cuerpos de los individuos pero también en la población para convertirse en mecanismos disciplinarios más sutiles con el objetivo de la obtención de la normalización, subordinación y docilidad de dichos cuerpos (FOUCAULT, 2002).

\section{EL FASCISMO ITALIANO Y LA OPERA NAZIONALE BALILLA}

El joven, el cuerpo juvenil robusto, uniformado, altivo, funcionaba como eficaz dispositivo simbólico, donde tomaba un valor universal y absoluto. Más allá de los límites históricos y cronológicos, el cuerpo juvenil ha sido exhibido en la mayoría de corrientes y movimientos políticos como fuente de progreso, de fuerza, de vida. Así se afirmaba también en la prensa de la Italia fascista de Mussolini, "nuestra juventud es el símbolo que domina, desvinculado del espacio y del tiempo: en él se resume el amor y la belleza, la fuerza y el canto"

La juventud y su eternidad servían para mostrar una nación perpetuamente joven, donde los cuerpos juveniles suponían un símbolo de esa "estirpe" tan valiosa para el fascismo, que se manifestaba en la elección política de un régimen que había hecho de los jóvenes el punto de apoyo de su acción y el centro de su sistema organizativo (MALVANO, 1996, p. 313). La juventud se convertía, así, en un elemento constitutivo del fascismo, adquiriendo una dimensión totalmente simbólica.

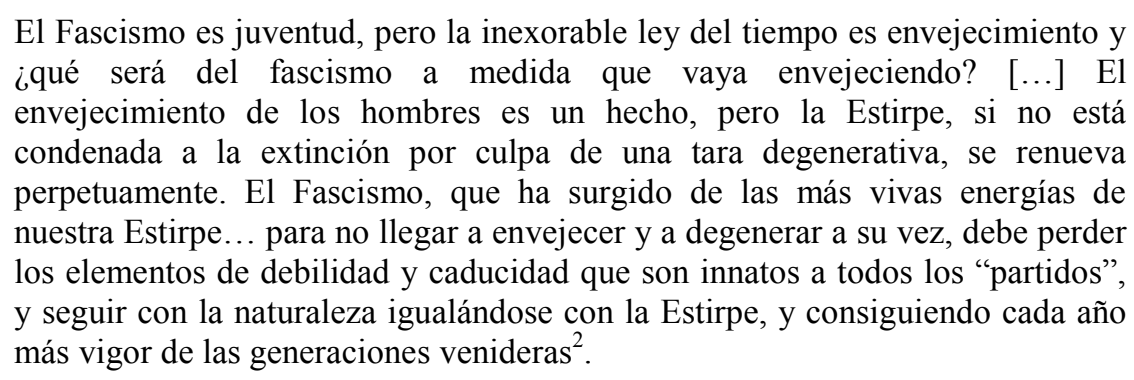

El discurso médico del fascismo se difundió, de manera escolar y extraescolar, a través de la Educación Física, donde la Opera Nazionale Balilla (ONB) asumía sus competencias fundamentales. Como afirmaba la prensa de la época, "del fascismo fuerza viva es la práctica deportiva"3; el deporte se ritualizó y se convirtió en un estilo de vida, el deporte no solo era una mera competición sino que también suponía una educación indispensable para

\footnotetext{
${ }^{1}$.La giovinezza è un símbolo. Gioventù Fascista (10 de febrero de 1932), 4.

${ }^{2}$ Morgagni. La leva fascista certeza del futuro. Rivista Ilustrata del Popolo d' Italia (abril de 1927), 5.

${ }^{3}$ Il Balilla (28 de febrero de 1929).
} 
la masa, para el colectivo, donde el joven se sentía parte del proyecto político que estaba simbolizando (MARTIN, 2004, p. 31). El joven era el protagonista de la práctica deportiva, donde desfilaba, marchaba con la cabeza erguida, haciendo uso de una retórica corporal del honor tan vistosa en los fascismos, "el paso de los jóvenes debe ser tan ágil y veloz que expresa la energía, el atletismo y la perfecta forma física [...] En la carrera no existen solo velocidad y desarrollo de la armonía, también está representado el símbolo de la acción rápida y del movimiento constante del fascismo"

Es impensable aludir a las enfermedades escolares del fascismo sin acudir a la idea del deporte y de la Educación Física como mejora de la raza y como prevención contra cualquier enfermedad que pudiese darse. Estudiando y analizando las interacciones que rigen la vida social. El discurso de la higiene escolar durante el fascismo permitía articular representaciones concretas del cuerpo, su valor simbólico y sus prácticas de perpetuación. Para el mantenimiento del cuerpo en el fascismo se pusieron en funcionamiento todo un conjunto de prácticas que tenían que ver con cuestiones de salud y de higiene, utilizando la excusa de la salud para amoldar los cuerpos de los jóvenes a estándares estéticos y de rendimiento muy concretos.

El objetivo era lograr una normalización de los cuerpos de niños y jóvenes, excluyendo a los considerados como "anormales" por no tener una buena eficacia productiva. El mantenimiento de un cuerpo saludable recubre el conjunto de las prácticas cotidianas, como la alimentación, los ejercicios, la sexualidad, tanto como actitudes generales de salvaguarda, de estrategias conservadoras o de propósitos predictivos.

Así, el principio organizador de las prácticas de mantenimiento - centrado sobre todo en el deporte y la gimnasia - se fundían en el límite colocado entre lo sano y lo malsano, fluctuante también según las mutaciones de concepción del cuerpo (VIGARELLO, 2005). La distinción entre malo y bueno por los fascismos no era sino una aplicación de las definiciones de lo sano y lo malsano.

Uno de los elementos esenciales en la formación de los jóvenes encuadrados en la Opera Nazionale Balilla era la asistencia sanitaria y médica, al igual que ocurría en las otras organizaciones juveniles fascistas europeas, era practicada por profesionales de la salud que se prestaban gratis a las visitas de atención sanitaria, incluso con atención domiciliaria y ambulatoria, así como su con su presencia en los campamentos, los mítines y donde quiera que estuvieran los jóvenes que necesitasen cualquier atención facultativa. La salud, se

\footnotetext{
${ }^{4}$ Sfilare di corsa. Gioventù Fascista (10 de febrero de 1933).
} 
convirtió en un elemento sustancial en el discurso normalizador del fascismo ya que, aquellos niños que no cumplían esos cánones físicos o estéticos - mediatizados en muchos casos por las enfermedades - no eran bien recibidos por las organizaciones juveniles que los “desechaban" por sus condiciones físicas.

\section{“NUESTRO CUERPO NO NOS PERTENECE, ES DE LA NACIÓN". LAS JUVENTUDES HITLERIANAS EN LA ALEMANIA NAZI}

Las Hitler Jugend o más conocidas en España como Juventudes Hitlerianas fueron instituidas en 1922. Tras el ascenso de Hitler al poder en 1933 estas organizaciones tomaron tal importancia que en 1936 ya contaba con más de cinco millones de afiliados. El servicio activo pasó de ser de carácter voluntario a obligatorio: todos los niños y niñas debían servir en esta organización de manera forzosa, al igual que ocurría en el Frente de Juventudes durante la etapa franquista o en la Italia de Mussolini con los niños entre ocho y dieciocho años.

Como explica Michaud (1996, p. 352) los estudios de "ciencia racial" se introdujeron en las escuelas a partir del 13 de septiembre de 1933, con la sumisión del personal docente al Führerprinzip que establecía la obligatoriedad del juramento al Führer en todas las disciplinas, confeccionando los hábitos cotidianos de la infancia y juventud del nazismo.

En las aulas también se realizaban las conocidas como "mediciones de caja craneana" para aprender a identificar "la expresión cobarde y pérfida" de sus compañeros judíos. Un examen corporal constante coaccionaba a los jóvenes, sus cuerpos debían estar siempre perfectos, normalizados según los cánones estéticos que marcaba el III Reich, para convertirse en futuros soldados o ciudadanos útiles que sustentaran el régimen fascista y su proyecto político.

Para los ideólogos nazis, la raza no era la mera apariencia sino mucho más, raza era sinónimo de alma. El cuerpo mostraba de esta manera la verdad del alma, permitiendo un clima de sospecha generalizada sobre toda la población, que era examinada por los demás según sus características corporales. Las múltiples restricciones y humillaciones que se aplicaban a los escolares judíos, como la obligatoriedad de sentarse en bancos separados, los insultos o las privación publica de la distribución de leche durante el recreo cumplían una función pedagógica: fomentar el odio contra el diferente. 


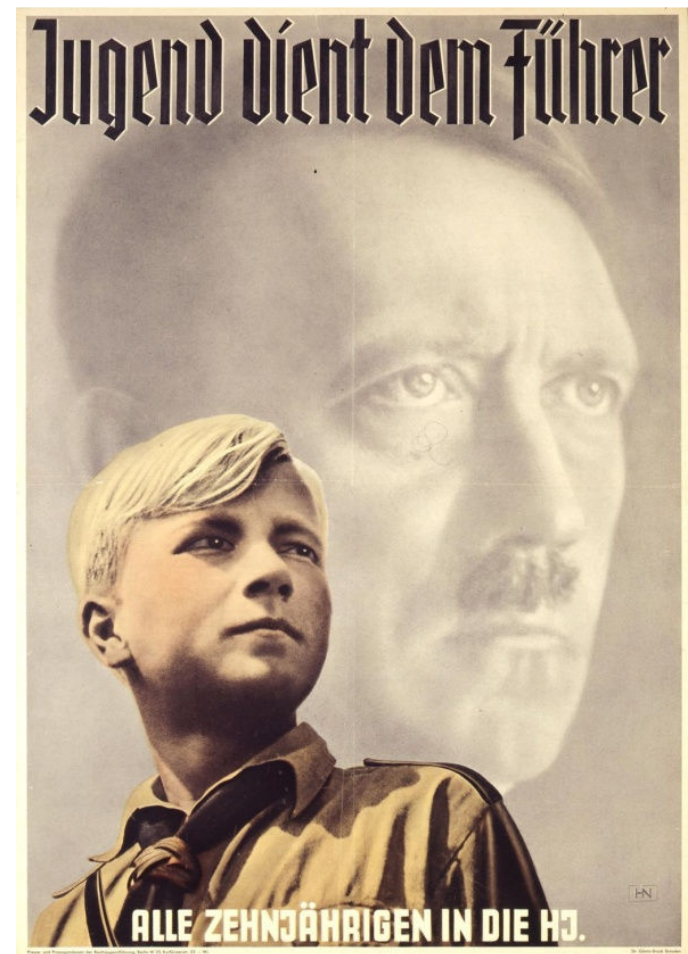

Cartel de propaganda de 1936, "la juventud sirve al Führer. Todos los muchachos de diez años a las Juventudes Hitlerianas". Coblenza, Bundesarchiv.

En las escuelas también se seleccionaban a aquellos niños que tenían alguna enfermedad o malformación, era la Eutanasia de los Niños, las denominadas como "matanzas de misericordia”. El Comité del Reich para el procesamiento científico de enfermedades congénitas encargó a numerosos pediatras y enfermeras que mandasen registros con posibles candidatos para el programa. Al valorar a los niños en las escuelas se rellenaban unos cuestionarios que -al igual que en los adultos- incluía posibles enfermedades congénitas, malformaciones, la raza, etc. El mismo Comité del Reich creó numerosas instituciones psiquiátricas en las que se crearon unidades pediátricas llamadas Kinderfachabteilugen - en estas unidades se internaban alrededor de 30 niños (LIFTON, 1988, p. 52).

Una de estas unidades se situaba en Kalmenhof donde la mortalidad infantil aumentó a partir de esta fecha de forma considerable, aunque la causa del fallecimiento oficial fueran “causas naturales" (LIFTON, 1988, p. 52). A pesar del aumento de la mortalidad, la unidad seguía llena, después una comisión decidía qué hacer con el niño enfermo: un $(+)$ de color rojo indicaba que el niño debía morir, y otro (-) de color azul que el niño se consideraba dentro de los límites de la normalidad aria.

Pero, ¿cuáles eran los cánones o requisitos que los implicados valoraban en la toma de decisiones? Normalmente, se basaban en los mismos requerimientos que en los adultos: un niño germano debía tener sangre pura alemana con sus antecesores y debía ser sano física y 
mentalmente. Más específicamente, la directiva estableció un guión de enfermedades no deseables y de probable traspaso al programa eutanásico como son: "enfermedades hereditarias serias como idiotez y mongolismo, sobre todo si está asociado a ceguera o sordera; microcefalia, hidrocefalia, o malformaciones de cualquier tipo" (LIFTON, 1988, p. $52)$.

Las enfermedades infantiles y juveniles durante el nazismo eran inspeccionadas a través de la escuela $y$, aquellos niños que presentaban algún problema de salud eran excluidos del sistema escolar para ser ingresados en instituciones especializadas. En la Alemania de Hitler, estar enfermo era igual a muerte. Los jóvenes que quería el nazismo eran robustos, sanos, fuertes y productivos.

Los jóvenes fueron uno de los pilares clave de las políticas nacionalsocialistas, encuadrados en las Juventudes Hitlerianas debían mantener a la Alemania eterna y joven, transmitiendo una promesa de liberación que les conducía al sometimiento de la máxima servidumbre. Las Hitler Jugend exigía de ellos unos signos, el cuerpo se convertía en el símbolo de lealtad al Führer, un cuerpo que debía estar sano, para legitimar una visión concreta - la visión de Hitler - que les permitía sentirme responsables de un proceso creador, glorioso y heroico.

\section{EL FRENTE DE JUVENTUDES DURANTE EL FRANQUISMO: "UN CUERPO FUERTE PARA ASEGURAR LA ESENCIA ESPAÑOLA"}

Como se ha señalado, el cuerpo se ha visto siempre atravesado por sistemas de regulaciones, a través de saberes y dispositivos, y se ha visto siempre imbuido en un campo político. Es innegable que este campo político se incrementó en los fascismos, que instrumentalizaron completamente el cuerpo de los jóvenes para ponerlo al servicio de la ideología.

En el caso del franquismo, el Frente de Juventudes ${ }^{5}$ - emulando a las Hitler Jugend o a la Opera Nazionale Balilla - controló a los jóvenes encuadrados forzosamente en la organización juvenil a través de sus cuerpos; el cuerpo se convertía en un aptitud, en una capacidad, por la que el joven debía mostrar su lealtad al Estado. Asimismo, los saberes científicos relacionados con la salud se utilizaron como una potente metáfora para expresar el

\footnotetext{
${ }^{5}$ Ley del 6 de Diciembre de 1940 instituyendo el Frente de Juventudes, BOE 7 de diciembre de 1940. El Frente de Juventudes tuvo una vida institucional de 1940 a 1960, cuando pasó a convertirse en la OJE (Organización Juvenil Española).
} 
temor al desorden y a la desintegración social. Una salud que no era similar si se aplicaba a hombres o a mujeres, y que a su vez era relacionada con emociones que fueron mediatizando la autopercepción y la experiencia corporal generando una determinada sensibilidad.

El Frente de Juventudes ${ }^{6}$ puso el cuerpo del joven en un lugar protagónico dentro de su práctica pedagógica, y con el deporte - como agente de propaganda fascista - y la Educación Física - como agente disciplinador - se fue creando una serie de rituales escolares y extraescolares que impregnaron la vida cotidiana de la infancia durante los años de la dictadura franquista. Incluso la propia Ley de enseñanza primaria de 1945 ya indicaba en su título primero que la existencia de la Educación Física en la enseñanza primaria es una necesidad, pero no solo "en lo que atañe al cultivo de las prácticas higiénicas, sino en lo que esta educación representa fisiológicamente para formar una juventud fuerte, sana y disciplinada"?

Esta idea del cuerpo sano e higiénico ya provenía del modelo histórico biológico del cuerpo humano, según este paradigma el cuerpo sano es aquel esbelto, fuerte, con destrezas y aptitudes, convirtiéndose en un cuerpo adiestrado e instrumental; una racionalización de cuerpo sometido a cánones prefijados socialmente (SCHARAGROSKY,1998, p. 22). Una de las consecuencias que trajo consigo este modelo, así como la introducción de la Educación Física y del cuerpo en la pedagogía moderna, fue la creación del "elitismo motriz" (BARBERO GONZÁLEZ, 1994) dejando de lado a los que no eran considerados "buenos", "sanos" o "adecuados" por el régimen político.

Era una observación del cuerpo a partir de fines sanitarios, bajo la excusa del correcto crecimiento biológico de los jóvenes, y bajo la premisa de que el cuerpo debía cuidarse meticulosamente para convertirse en un instrumento del Estado en el mañana. Uno de los referentes médicos durante el régimen franquista, el Dr. Jerónimo Tirado, argumentaba también la labor que debía tener el médico en el espacio escolar: "todas las actividades del niño en el medio escolar, todo cuanto le rodea, la enseñanza misma, requieren la tutela del médico, que debería establecer las medidas higiénicas oportunas para conseguir un mayor aprovechamiento del alumno" (POLO, 2007, p. 145).

\footnotetext{
${ }^{6}$ Todos los escolares debían formar parte, obligatoriamente, del Frente de Juventudes y debían realizar todas las actividades que puso en marcha esta organización juvenil en la escuela. Pero no debemos confundir a los encuadrados obligatoriamente con los afiliados, ya que estos últimos eran los jóvenes que pagaban cuota y que formaron las llamadas Falanges Juveniles de Franco; su labor no se relegaba solo a la escuela sino también a otros espacios fuera del escolar. Serían los miembros de las FFJJFF los que se organizaron en varias secciones: Flechas, Cadetes y Guías y los que realizaron actividades con el objetivo de convertirse en futuros falangistas. ${ }^{7}$ Ley de 17 de julio de 1945 sobre Educación Primaria, BOE 18 de julio de 1945.
} 
De esta manera, se introduce en España el concepto alemán de Heilpädagogik, que hace mención a una "pedagogía médica" cargada de higienismo racial y que pretendía una normalización social de los cuerpos. Según Antonio Polo, esta normalización tenía dos niveles: por un lado afectaría a aspectos macro-actitudinales como el fomento de la espiritualidad, de la evangelización de los esquemas reproductivos o del desarrollo del ideal de caballero. Por otro lado, esta normalización también conllevaría el fomento de aspectos micro-actitudinales como los modos de sentarse, de vestir, de coger el lápiz o la tartamudez (POLO, 2007). Dentro de esta normalización de los cuerpos, la escuela debía crear un ejército uniformado de alumnos diestros, con una postura adecuada, caballerosos y buenos oradores.

La moralización y medicalización del cuerpo era, efectivamente, ideológica: el cuidado del cuerpo y sus beneficios remitían a una especie de benevolencia universal de la que nadie podría negarse. La salud y control a través del cuerpo era vinculada al bien, al desarrollo de la raza, a la virilidad y la fuerza, mientras que el deterioro físico, el no tener un cuerpo vigoroso y hercúleo era asociado al mal. Esta dicotomía bien-mal será usada hasta la saciedad por el Frente de Juventudes como modo de adoctrinamiento físico.

Esta jerarquización y distinción entre unos jóvenes y otros, según sus parámetros físicos, pretendía la circulación de un discurso y unas prácticas conforme a unos mecanismos completamente ideologizados que dieron paso a una construcción concreta de la realidad; esta construcción vendría a ser - según Foucault - lo que llamamos normalización. Para que existiera un cuerpo normalizado, también tenía que haber unos cuerpos "anormales", aquellos que no cumplían con los estándares de belleza que establecía la organización juvenil franquista.

Además, esta normalización buscaba un perfecto equilibrio entre esos tres elementos tan apreciados por el Frente de Juventudes, el cuerpo, la mente y la moral:

El individuo se educa física, moral e intelectualmente. El cuerpo y el espíritu se
desarrollan siguiendo un ritmo común, presentando particularidades y
manifestaciones propias a cada estado y toda desviación o predominio de una
de las tres partes del todo que forma el organismo humano da un desequilibrio,
y por lo tanto una anormalidad en el individuo ${ }^{8}$.

El cuerpo se convertía, así, en un texto donde se escribía la realidad social. De esta manera, la relación entre ejercicio físico y salud imponía un estilo de vida que marcaba cómo los jóvenes debían moverse, cómo vestir, cómo respirar, cómo descansar, cómo trabajar, etc. Se pretendía la homogeneización de los gestos y de los gustos haciéndolos coincidir con las

${ }^{8}$ Cartilla escolar de Educación Física de 1945 (Madrid: Delegación Nacional del Frente de Juventudes, 1945), 29. 
exigencias de la sociedad del momento; se impuso un estilo de vida normalizado, una salud planteada por los demás. Así se explica en la Cartilla escolar de Educación Física:

\begin{abstract}
Comprende entre los ideales de Educación Física: un ideal vitalista o biologista respecto a asegurar la salud del niño y favorecer su crecimiento y desarrollo. Un ideal práctico referente a mejorar sus condiciones, cualidades y actividades físicas, haciéndole apto físicamente para todas las cosas. Y un ideal social y político en cuanto a formarles en un estilo y con unos fines, para que llegue a ser buen productor o soldado. Hoy día es necesario para vosotros el vigor, la fuerza, el valor y el endurecimiento y la aptitud para la lucha. Todo ello se consigue en las prácticas físicas?.
\end{abstract}

\title{
CONSIDERACIONES FINALES: EL JOVEN SANO Y NORMALIZADO COMO SÍMBOLO POLÍTICO DEL FASCISMO
}

Como ya apuntó Vigarello (2005), el cuerpo y su estudio son un laboratorio privilegiado para las ciencias humanas, de ahí que el estudio de la historia del cuerpo radique en "tratar de historiar lo que no parece tener historia, o lo que no parece digno de tener historia. Por eso es importante hacer visible lo que a menudo es invisible para los observadores y lo es casi siempre para nosotros" (ROCHE, 1996, p. 78).

Durante los fascismos, el cuerpo tomó un papel protagónico, siendo el blanco de distintos saberes y prácticas, que buscaban formar a los jóvenes en las técnicas militares, docilizar sus cuerpos y aprovecharse de las posibilidades que le ofrecía la imagen de una juventud eterna como fuente de legitimidad política. Los dos discursos, tanto el del militarismo - que adquirió verdadera fuerza en la ONB con el uso de armas reales - como el de la salud médica - con el racismo de por medio en el caso de las Hitler Jugend -, sustentaron y legitimaron toda la practica pedagógica y adoctrinadora de las organizaciones fascistas juveniles en el aspecto moral y corporal.

Para el fascismo, el cuerpo pertenecía al Estado, a la Patria, con el objetivo de conseguir unos jóvenes fuertes y sanos que pudieran sostener con sus torsos musculosos el peso del Estado fascista y su expansión política. Una parte importante del discurso sobre el cuerpo en los fascismos europeos se relacionó con la higiene y la salud, que legitimó - bajo un aparente rigor científico - el control de los cuerpos de niños y jóvenes para lograr establecer estándares de belleza y perfección con el objetivo de lograr una normalización de los cuerpos. La racionalización del cuerpo, llevó a que éste se construya en un objeto de análisis de rendimiento, con el objetivo de aumentar su productividad para ser útil instrumento del

\footnotetext{
${ }^{9}$ Cartilla escolar de Educación Física, 21.
} 
Estado.

Hablamos entonces de la puesta en marcha de unas políticas públicas del cuerpo, a través de las cuelas se daba continuidad a la relación entre salud y progreso. La relación entre una política educativa - practicada a través de las organizaciones fascistas juveniles - y una política del cuerpo impondrá una serie de intervenciones sobre los jóvenes sustentadas sobre la idea del progreso de la sociedad.

El tratamiento del cuerpo en lo cotidiano tiene que ver así con la representación dominante del cuerpo, que explica sus funcionamientos, y por tanto su mantenimiento. Pero las nociones mismas de enfermedad y de salud, antes incluso de pensar en las prácticas que buscan perpetuar una y alejarse de la otra, no son reducibles a las causas biológicas, y comportan una fuerte dimensión social y simbólica.

En la cosmovisión totalitaria el ser humano era moldeable como la cera, y sus máximos dirigentes los encargados últimos de la misión histórica de la forja del hombre nuevo. El joven fascista proyectaba en su cuerpo los signos y señales de las mutaciones de su cultura, aprehendidos de manera cotidiana sin ser consciente del potente vehículo corporal de transmisión ideológica en el que se convertía.

\section{BIBLIOGRAFÍA}

BARBERO GONZALEZ, José. Materiales de Sociología del Deporte. Madrid: La Piqueta, 1994.

CARTILLA escolar de Educación Física de 1945 (Madrid: Delegación Nacional del Frente de Juventudes, 1945).

COURINE, Jean-Jacques. Introducción. En: CORBIN, Alain; COURTINE, Jean-Jacques y VIGARELLO, Georges (coords.): Historia del cuerpo. El siglo XX. Las mutaciones de la mirada. Madrid: Taurus, 2005. (vol. III)

FOUCAULT, Michel. Vigilar y castigar. Madrid: Siglo XX Editores, 2002.

IL BALILLA, 28 de febrero de 1929.

LEY del 6 de Diciembre de 1940 instituyendo el Frente de Juventudes, BOE 7 de diciembre de 1940.

LEY de 17 de julio de 1945 sobre Educación Primaria, BOE 18 de julio de 1945.

LA GIOVENEZZA è un símbolo. Gioventú Fascista, 10 de febrero de 1932.

LIFTON, Robert Ray. The nazi doctors. Medical Killing and the Psychology of Genocide. Cambridge: Harvard University Press, 1988. 
MALVANO, Laura. El mito de la juventud a través de la imagen: el fascismo italiano. En: LEVI, Giovanni y SCHMITT, Jean-Claude. Historia de los jóvenes. La Edad Contemporánea. Madrid: Taurus, 1996, p. 313-346.

L'immagine di massa: il culto del Duce. En: MALVANO, Laura. Fascismo e politicadell' immagine. Piamonte: Bollati Boringhieri, 2002.

MARTIN, Simon. Football and Fascism. The national game under Mussolini. Oxford: Berg, 2004.

MICHAUD, Eric. Soldados de una idea. Los jóvenes bajo el Tercer Reich. En: LEVI, Giovanni y SCHMITT, Jean-Claude: Historia de los jóvenes. La Edad Contemporánea. Madrid: Taurus, 1996, p. 349-375.

MORGAGNI. La leva fascista certeza del futuro. Rivista Ilustrata del Popolo d'Italia, abril de 1927.

POLO, Antonio. El concepto de Heilpädagogik y su introducción al contexto español. Historia Actual Online, n 12, p.143-150, 2007.

ROCHE, Daniel. La cultura material a través de la historia de la indumentaria. Historiografía francesa. Corrientes temáticas y metodologías recientes. Méjico: Universidad Iberoamericana, 1996, p. 77- 88.

SCHARAGROSKY, Pablo. Algunas reflexiones sobre el cuerpo durante el franquismo. Educación Física y Ciencia, 4, p. 20-49, 1998.

SCIFONI. L’ italiano nuovo. Gioventú Fascista, 1 de febrero de 1934.

SFILARE di corsa. Gioventù Fascista, 10 de febrero de 1933.

TIRADO, Jerónimo Bautista. Higiene de la lectura y la escritura. Semana Médica Española, 236.

VIGARELLO, Georges. Corregir el cuerpo. Historia de un poder pedagógico. Buenos Aires: Nueva Visión, 2005.

VILLANOU, Conrad. Imágenes del cuerpo humano. Apunts: Educación Física y deportes, $\mathrm{n}^{\mathrm{o}}$ 63, p. 94-104, 2001. 